\title{
Obstructive Sleep Apnea -An Orthodontic review
}

\author{
Dr. Sathish Kumar N, Dr. Divya.K, Dr. Appasaheb Naragond, \\ Dr. Smitha Naragond, Dr. K. Rajasigamani, Dr. V. Baskar \\ (Assistant Professor \& HOD Department of Dentistry, SVMCH \& RC, Ariyur,Puducherry, India) \\ (Assistant Professor \& Department of Emergency Medicine, SVMCH \& RC,Ariyur, Puducherry, India) \\ Reader (Department of Orthodotic \&Dentofacial orthopedics Vasantdada Patil dental College and Hospital \\ Kavalapur-Sangli) India \\ Senior Lecturer Dept.Of Conservative and Endodontics Vasantdada Patil dental College and Hospital \\ ,Kavalapur -Sangli) India \\ Hod,Prof Department of Orthodontics and Dentofacial Orthopedics, RajahMuthiah Dental College and \\ Hospital, Chidambaram, Tamil Nadu, India \\ Profesor Department of Orthodontics and Dentofacial Orthopedics, RajahMuthiah Dental College and \\ Hospital, Chidambaram, Tamil Nadu, India
}

\begin{abstract}
Obstructive Sleep Apnea is caused by an interplay between a variety of factors, including sleep related loss of muscle tone in the tissues supplied by the glossopharyngeal nerve,, anatomical obstruction of the nasal passages, large tonsils, large tongue, a retrognathic Mandible, obesity, alcohol, sedative medication, allergies. The orthodontic approach is intended to provide patients with immediate relief from OSA, as well as changes to the airway that may address an underlying cause. It can be treated using surgery, continuous positive airway pressure and oral appliances therapy. This article review some of the basic aspects of this sleep-related disorder, its diagnosis and treatment modalities.
\end{abstract}

Keywords: Orthodontics, Obstructive Sleep Apnea, mandibular advancement, Oral appliance, CPAP

\section{Introduction:}

Snoring sound is produced by the vibration of the soft palate or other oropharyngeal tissues, it can became a medical concern because it is key symptom of OSA. Disease is characterized by upper airway obstruction, associated with repeated gaps in breathing and interrupted sleep. Cessations of breathing for 10 seconds or longer are termed apneas (from greek- without breath), When 30 or more apneic episodes occur in the course of seven hours of sleep, resulting in excessive sleepiness during the working hours, a person is described as having sleep apnea syndrome. This may begin at any age, but incidence increases with age. Anatomic factors that can contribute to OSA are maxillary or mandibular retrognathism, increased lower facial height, large tongue elongated soft palate, inferiorly positioned hyoid bone. This points out how critical the role of orthodontist can be in diagnosing and treating OSA.

The first description of this disorder in the medical literature was in 1965. effective treatment that modify these health risks have emerged. Although continuous positive airway pressure (CPAP) is the most efficacious treatment. It requires the used of a mask interface, sealed tubing, and a device connected to a power source. This complexity limits its acceptance by patients and leads to suboptimal treatment adherence. Oral appliances are a simpler alternative to CPAP for the treatment of Obstructive sleep

Apnea (OSA). They are often considered by patients to be a more acceptable treatment modality compared to CPAP. As they are quiet, portable, and do not require a power source,. While the role of oral appliances for the treatment of OSA was unclear in the past, this has changed dramatically. There are served modalities of treatment for obstructive sleep apnea. The use of the oral appliances for management of airway obstruction started in 1900 when the French stomatologist Pierre Robin used oral appliances to manage upper airway obstruction of neonates born with Pierre Robin syndromes.

\section{Pathophysiology}

It has been hypothesized genioglossal that individuals with OSA have impaired genioglossal function, allowing the prolapse of the tongue against the posterior pharyngeal wall with inspiratory effort during sleep.

The situation now appears to be more complicated - evidence suggests that an invagination of the pharyngeal walls and a general hypotonia of the dilating muscles of the upper airway can also be involved in allowing airway occlusion during sleep. The nasal airway can also play an important role in total airway occlustion. Nasal obstruction increases resistance to air flow, which in turn results in increased inspiratory effort and greater negative pressure in the pharyngeat airway. This suction increases the likelihood of collapse of the pharyngeal airway. Various factors which predispose to obstructive sleep apnea, the most important 
being obesity structural abnormalities in the face, skull, or airways that cause some obstruction or collapse in the upper airways and reduce air pressure can produce sleep apnea syndrome. People with micorgnathia, adenoids, retrognathia, enlarged tonsils, tongue enlargement, acromegaly and longer anterior facial height are especially predisposed to obstructive sleep apnea.

\section{Symptoms;}

Snoring (OSA is unlikely in the absence of habitual snoring)

Apneic pauses (choking, gasping, snoring during the night)

Restless leg syndrome (RLS) restless sleep and increased body movements

Bruxism (nocturnal tooth grinding)

Nocturnal and daytime enuresis

Sleep position (side and stomach sleepers) or neck hyper extended

Growth failure restriction

Sleep walking or sleep terrors

Obesity

Daytime symptoms can include:

Mouth breathing, due to adenoidal hypertrophy, and dry mouth

Chronic nasal congestion ,rhinorrhea

Adenotonsillar hypertrophy

Hyponasal speech ,Fatigue

Excessive daytime sleepiness: difficulty waking or falling asleep at school

Mood changes; ireitability, low frustration tolerance, impatience, depression anxiety, and social withdrawal, a

negative sense of well being

Acting-out beaviors including aggression and hyperactivity

Cognitive impairment and poor school performance

Inattention, poor concentration, and distractibility

ADHD-like symptoms

Infraorbital venous congestion

\section{Diagnosis;}

A patient is suspected of having OSA, the diagnosis is confirmed by an overnight polysomnography (PSG), commonly referred to as a sleep study. Communicate this recommendation to the patient's physician. If the patient refuses a sleep study, he recommends having the patient sign a waiver prior to providing an oral appliance.

Once a sleep study is undertaken, the resulting data is the Respiratory Disturbance Index (RDI). This is a somewhat complex index that measures the number of apnic (total cessation of breathing) and hypopnic (shallow breathing) events per hour of REM and non REM sleep. For example, someone who has an RDI of 30 has 30 apnic or hypopnic events an hour. The range of RDIs is as follows. RDI $<5$ Normal RDI 5-15 Mild; RDI 15-30 Moderate: RDI> 30 Severe.

\section{ORAL APPLIANCE THERAPHY:}

\section{Treatment}

Orthodontic appliances are made in such a manner that it can be worn permanently or removeably depending upon the condition.. Appliance are designed to bring the mandible and tongue forward, opening up the lower pharynx to allow unrestricted breathing.

\section{INDICATIONS OF ORAL APPLIANCE THERAPY;}

Oral appliance are indicated for use in patients with primary snoring or mild OSA who do not respond or are not appropriate Candidates for treatment with behavioral measures such as weigh loss or sleep position change; Patients with moderate to servere OSA should have an initial trial of nasal CPAP because greater effectiveness has been shown with this intervention that with the use of oral appliances; Oral appliances are indicated for patients with moderate to severe OSA who are intolerant of, or refuse treatment with, nasal CPAP, oral appliances are also indicated for patients who refuse or who are not candidates for tonsillectomy and adenoidectomy, cranial facial operations or tracheostomy.

\section{ORAL APPLIANCES;}

Dental devices include tongue retaining devices (TRD) and mandibular advancement appliances (MAA). Tongue retaining device is a splint that holds the tongue in place to keep the airway as open as possible. Mandibular advancement device (MAA)(Fig.1) is by farther most common type of dental appliance in 
use today. It protrudes the mandible forward, thus preventing or minimizing upper airway collapse during sleep.Mechanism of action- oral appliances are worn only during sleep and they help to maintain an open and unobstructed airway by repositioning or stabilizing the lower jaw, tongue, soft palate or uvula. Mandibular advancement devices - as mentioned earlier the first use of mandibular advancement devices was suggested by Pierre Robin in 1903. it protrudes the mandible forward, thus preventing or minimizing upper airway collapse during sleep.(Fig.2)

Currently available appliances:

First category: one piece appliance with no ability to advance the mandible incrementally.

Second category: Appliance are principally tow piece in design and offer the potential for incremental advancement.

Third category: They permit incremental advancement and lateral movement of mandible.

Tongue retaining devices: Tongue retaining device is a splint that holds the tongue in place to keep the airway as open as possible. They are excellent devices for patients with Temperomandibular joint sensitivity. There are several advantages of Tongue retaining devices, they do not require retention from dentition, minimal adjustments are required and cause minimal sensitivity to teeth and temperomandibular joint.

\section{Advantage of Oral appliances:}

Significant reduction in apneas for those with mild-to-moderate apnea, they may also improve airflow for some patient with severe apnea, improvement and reduction in the frequency of snoring and loudness of snoring in most patients and higher compliance rates than with CPAP.

\section{Disadvantages of Oral appliances:}

Mandibular advancement splints generate reciprocal forces on the teeth and jaw that can result in acute symptoms, as well as long-term dental and skeletal changes. While mandibular advancement splints are primarily attached to the dental arches, most extend beyond these and thus apply pressure to the gums and oral mucosa. The incidence of reported side effects and complications vary significantly between studies. This is probably due to difference in the type of oral appliance used, the design of the oral appliance, the degree of mandibular advancement, as well as the frequency and duration of follow-up.

During the acclimatization period, it is common for adverse effects to develop, which are usually minor and self-limiting. These include execessive salivation, mouth dryness, tooth pain, gum irritation, headaches, and temporomandibular joint discomfort. Patients should have regular visits with a health professional to check the devices and make adjustments:.

\section{SKELETAL SURGERY:}

Surgical correction of the jaw position is the most effective treatment for OSA, with good long-term stability. Skeletal surgery can involve maxillary and mandibular expansion and/or maxillary and mandibular advancement. Orthognathic surgery primarily involves advancements usually have to be over $10 \mathrm{~mm}$ to be effective in treating OSA, so, typically maxillay advancement is also necessary.

\section{SOFT TISSUE SURGERY:}

Another procedure that has been used is the uvulopalatopharyngoplasty (UPPP) the reconstruction of the throat by resecting te posterior margins of the soft palate and redundant mucsosa on the lateral pharyngeal walls. Unfortunately, the success rate for this approach to sleep apnea is only $40 \%$ because obstructions at other sites are not affected.

\section{CPAP:}

A continuous positive airway pressure machine (CPAP) is a new device with a mask that fits snugly over the sleeper's nose. It sends a continuous stream of air under positive pressure that is adjusted for each person using it to hold the throat open through the night. 


\section{Obstructive sleep apnea}

\section{Advancement of mandible}
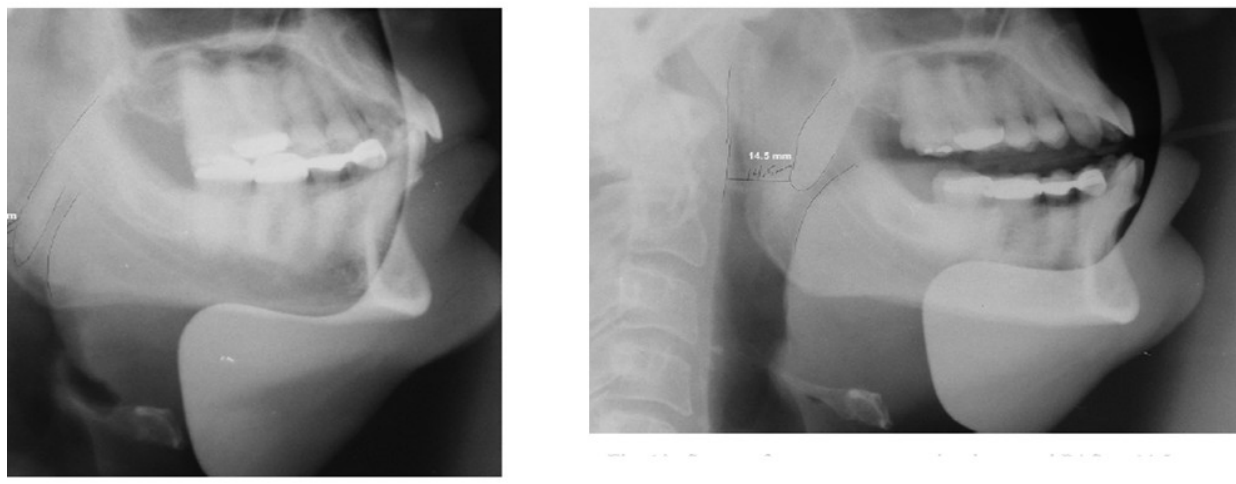

Baseline: narrow PAS of $6 \mathrm{~mm}$.

Figure.01 PAS increased after advancement

\section{Figure.02}

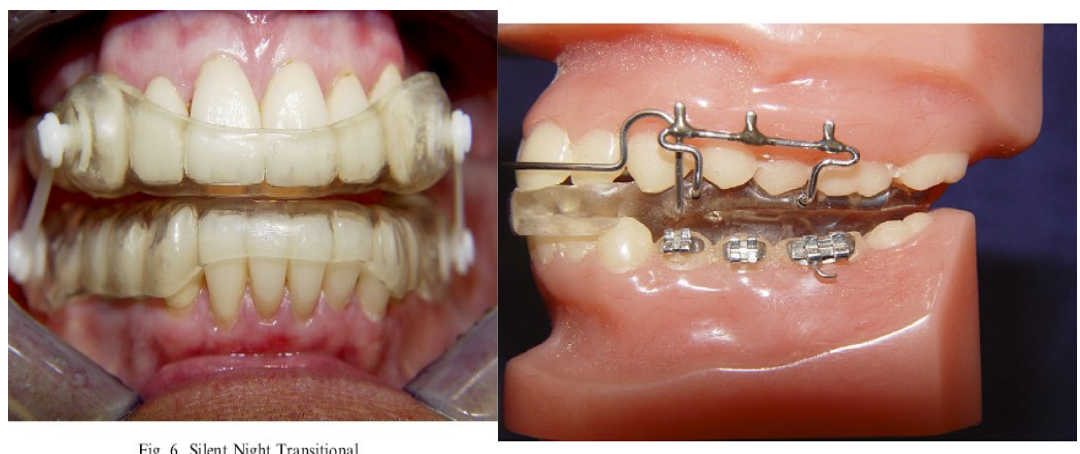

Fig. 2. BioCorrector $\mathrm{TMJ} /$ jaw repositioning splint.

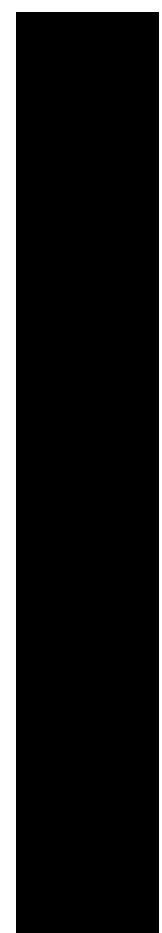

Oral Appliance for OSA

\section{Summary And Conclusions}

OSA is characterized by breathing and sometimes pronounced body and arm movements. The victim may wake up suddenly with choking sensations, gasping for air, or in a sweat, other symptoms may be frequent napping during the day, especially in inappropriate places (like meetings, or while driving), memory problems, lack of concentration, high blood pressure..... Many of these symptoms can also be caused by many other conditions, so diagnosis may be difficult. Orthodontic diagnosis may discover anatomic conditions that could cause this condition. Enlarged tonsils or adenoids in a lateral cephalometric radiagraph, or maxillary width 
deficiency and narrow nasal cavity in a P.A. radiograph, are indications for questioning the patient about other symptoms. If obstructive sleep apnea is suspected, a medical consultation is in order. It is important to distinguish between central and mixed sleep apnea. CENTRAL sleep apnea involves a cessation of respiratory effort, as well as reduced air flow. This condition is relatively rare. MIXED sleep apnea might involve two hundred obstructive and twenty kinds of central apneas, so some A.C. P's group them together as mixed apneas. The belief is that the central apneas in the [category are a secondary effect of the reduced air flow caused by the obstruction rather than a primary etiologic factor.

OSA is simply rendered ineffective by the obstruction. It is in this condition that the orthodontist may best participate in relieving or curing the symptoms. Developments have been reflected in the updated practice parameters of the American Academy of Sleep Medicine, which now recommend the use of oral oppliances for mild-to-moderate OSA, or for patients with servere OSA who are unable to tolerate CPAP or refuse treatment with CPAP. With this review article we research should focus on determining the influence of the design of oral appliances on clinical outcome, the development of a clinically reliable method for identifying those patients who are most likely to achieve a favorable treatment response, and the characterization of facotors predisposing to long-term adverse effects of oral appliance treatment.

\section{Bibliography}

[1]. Guilleminault, Christian, 1985, “Obstructive sleep apnea”, Med Clin, N.AM 69-1187-1203.

[2]. Guilleminault, Cand Dement, W.C. 1978 “sleep apnea Syndromes,” Kroc Foundation Series, Vol 11,Newyork Alan R.Liss.

[3]. Kales, A, Bider, E.O. Cadieux, R.J. etal/1984, Sleep apnea in a hypertensive population.Lancet.2.1005-1008

[4]. Cistulli PA, Sullivan CE "Pathophysiology of sleepapnea" In :Saunders NA, Sullivan CE, eds. Sleep and breathing, Newyor, NY: Marcel Dekker, 1994:405-448.

[5]. Bilwise, D.I, and Pascualy, R.A 1984, "Sleep -related respiratory disturbance in elderly persons",Compr Ther, 10(7):8-14.

[6]. Cortese S, Konofal E, "Sleep and alertness in children with attention - deficit/hyper activity disorder :a systemic review of literature." Sleep 2006:29:504-511.

[7]. Peltinaju T. "The effect of mode of breathing on crantiofacial growth-revisited", Eur J Orthod 2007;29-426-429.

[8]. Alexandar, J.K. Guthrie, A.E., 1959 "Lung volume changes with extreme obesity".Clin. Res 7;171-176.

[9]. Schwab RZ, Gupta KB. "Upper airway soft tissue anatomy in normal and patients with sleep disordered breathing: Significance of the lateral pharyngeal walls " Am J Respir; criti care med 1995; 152;1673-89.

[10]. Alexander J.K Amad, H, "Observations on some clinical features of extreme obsecity, with particular reference to cardiorespiratory effects", Am J. Med.32:512-517.

[11]. Moran, W.B and Orr, W.C 1985 "Diagnosis and management of obstructive sleep apnea", Part-II Arch Otolaryngol. 111(10): 650658 .

[12]. Bornstein SK, "Respiration during sleep polysomnography.' Addision - Wesley; 1982 p.183.

[13]. Dillon JE, Blunden S "Diagnosis and obstructive sleep apnea in children before and one year After adeno tonsillectomy". J Am Acad child Adolesc Psychiatry 2007;46;1425-36.

[14]. Gastaut H, Tassinari CA, Duron B, "Polygraphic study ofdiurnal and nocturnal (hypnic and respiratory) episodal manifestations of Pickwick syndrome". Rev Neurol (paris) 1965; 112:568-579

[15]. Cistulli PA, Grunstein RR. "Medical devices for the diagnosis and treatment of obstructive Sleep Apnea". Expert Rev Medical Dev $2005 ; 2 ; 749-763$.

[16]. Mimi Yow, "Overview of oral appliances and managing the airway in obstructive sleep apnea".Semin orthod. 2009;15: 88-93.

[17]. Cistulli PA,Gotsopoulos H. "Treatment of snoring and obstructive sleep apnea with mandibular repositioning appliances" Sleep med rev 2004;8;443-57.

[18]. Ferguson KA, Rogers, “Oral appliance for snoring and obstructive sleep apnea: review” Sleep 2006;29;244-262.

[19]. Ng ATm , Gotsopoulos H "Effect of oral appliance theraphy on upper airway collapsibility in obstructive sleep apnea" Am J Respir Crit Care med 2003; $168 ; 238-241$.

[20]. Lowe AA “Oral appliance for the treatment of snoring and obstructive sleep apnea” J Can Dent Assoc 1999;65:571-574.

[21]. Oktay H,Ulukaya E , "Maxillary protraction appliances effect on the size of the upper airway passage" Angle orthod 2008;78;209214.

[22]. Usumez S, Orhan M “Effect of rapid maxillary expansion on nocturnal enuresis” Angle orthod 2003;73;532-538.

[23]. Kurol J, Modin H “Orthodontic maxillary expansion and effect on nocturnal enuresis" Angle orthod 1998;68;225-232.

[24]. Wei JL, Smith HJ. "Improved behavior and sleep after adenotonsillectomy in children with sleep disordered breathing" Arch Oto laryngol Head Neck Surg 2007;133;974-979.

[25]. Thawley, Stanley E 1985 "Surgical treatment of obstructive sleep apnea" Med. Clin. Of N.Am 69;1337-58.

[26]. Hamada T, Ono T "Mandibular distraction Osteogenesis in skeletal class II patient withobstructive sleep apnea" Am J Orthod Dento facial Orthop 2007; $131 ; 415-425$

[27]. Barnes M, MeEvoy RD, "Efficacy of positive airway pressure and oral appliance in mild to moderate obstructive sleep apnea" Am $\mathrm{j}$ Respir Crit Care Med 2004;170;656-664.

[28]. Weaver TE, Chasens ER "Continuous positive airway pressure treatment for sleep apnea in older adults", Sleep Med Rev 2007;11;99-111.

[29]. Mc Ardle N, Devereux G "Long term use of CPAP therophy for sleep apnea/hypopnea syndrome" Am J Respir Crit Care Med $1999 ; 159 ; 1108-1114$

[30]. Robertson CJ, "Dental and skeletal changes associated with long term mandibular advancement", sleep 2001;24;531-537.

[31]. Marklund M. "Predictors of long-term orthodontic side effects from mandibular advancement devices in patients with snoring and obstructive sleep apnea," Am J Orthod Dentofac Orthop 2006; 129;214-221. 